\title{
Трехмерная модель нефтегазовых резервуаров на основе обработки рассеянных сейсмических волн методом Гауссовых пучков
}

Чеверда В. А., Протасов М. И., Лисица В. В., Решетова Г. В., Петров Д. А., Мельник А. А., Шиликов В. В., Мельников Р. С., Волянская В. В.

\begin{abstract}
Аннотация
Эффективность разработки нефтегазового месторождения во многом определяется полнотой понимания его геологического строения. В последнее десятилетие все большее внимание привлекают сложно построенные карбонатные резервуары, обладающие коллекторами трещиноватого типа. Настоящая статья посвящена разработанной в ООО «РНКрасноярскНИПИнефть» совместно с Институтом нефтегазовой геологии и геофизики им. А.А.Трофимука СО РАН технологии построения трехмерных изображений сложно устроенных резервуаров в рассеянных сейсмических волнах с привлечением Гауссовых пучков. Для её апробации была построена специальная синтетическая модель, реалистично отображающая один из лицензионных объектов ПАО НК Роснефть. Для этой модели было выполнено полномасштабной трёхмерное сейсмическое моделирование, что обеспечило нас синтетическими волновыми полями и открыло возможность проведения полностью контролируемых численных экспериментов по реконструкции геологического строения изучаемого объекта.

Одной из отличительных особенностей построенной цифровой модели/цифрового двойника является представление разломов не как некоторых идеальных поверхностей скольжения, а в виде трёхмерных геологических тел, заполненных тектонической брекчией. Для моделирования такой брекчии и геометрии этих тел была выполнена серия численных экспериментов, моделирующих геомеханические процессы формирования разломов. Для подбора параметров используемого при этом метода дискретных элементов привлекалась информация, полученная путём геофизических исследований в горизонтальных скважинах, пересекающих разлом в пределах геологического прототипа построенной цифровой модели.
\end{abstract}

\section{Ключевые слова:}

карбонатный резервуар, трещиноватость, разломы, численное моделирование волновых полей, поле энергии рассеянных волн, Гауссовы пучки 


\title{
УДК 534-18+550.34.097
}

\section{Трехмерная модель нефтегазовых резервуаров на основе обработки рассеянных сейсмических волн методом Гауссовых пучков}

\author{
В.А. Чеверда ${ }^{1}$, М.И. Протасов ${ }^{1}$, В.В. Лисица ${ }^{1}$, Г.В. Решетова ${ }^{2}$ Д.А. Петров ${ }^{3}$, А.А. \\ Мельник $^{3}$, В.В. Шиликов ${ }^{3}$, Р.С. Мельников ${ }^{4}$, В.В. Волянская ${ }^{4}$ \\ ${ }^{1}$ Институт нефтегазовой геологии и геофизики им А.А.Трофимука СО РАН, 630090, \\ Новосибирск, просп. акад. В.А.Коптюга, 3 \\ ${ }^{2}$ Институт вычислительной математики и математической геофизики СО РАН, 630090, \\ Новосибирск, просп. акад.М.А.Лаврентьева, 6 \\ ${ }^{3}$ ООО РН КрасноярскНИПИнефть, 660022, Красноярск, ул. Партизана Железняка, 24в \\ ${ }^{4}$ ПАО НК Роснефть, 117997, Москва, Софийская набережная, 26/1
}

\section{ВВЕДЕНИЕ}

Для успешной разработки месторождений углеводородов необходимо глубокое понимание особенностей его геологического строения. В последнее время всё более широкое использование для решения таких задач приобретают рассеянные/дифрагированные волны. Нами в течение ряда лет проводились работы по созданию теории, численных методов и развитию технологии применения волн такого типа. Одной из основных проблем здесь является необходимость выполнения надёжной апробации разработанных подходов, допускающей независимую проверку. Самым надёжным способом для этого является построение цифровой геологической модели месторождения, его цифрового двойника, который описывает основные геологические элементы изучаемого объекта: его геометрию, стратиграфию, литолого-фациальная характеристику пластов-коллекторов, эффективные толщины, коллекторские свойства и другие. Знание этих особенностей приобретает особое значение при разработке карбонатных резервуаров, имеющих, как правило, весьма сложную структуру пустотного пространства. При разработке месторождений такого типа необходимо учитывать неравномерность распределения трещин и каверн, так как они выступают как главные пути фильтрации флюидов (трещины) и формируют ёмкостное пространство (каверны) в карбонатных резервуарах. Подобные залежи отличаются своим разнообразием и концентрируют весомую часть мировых запасов углеводородов: до 60\% нефти и 40\% газа [Characterization of Fractured Reservoirs, Schlumberger, 2007]. На территории Российской Федерации, такие месторождения распространены в пределах Сибирской платформы, Волго-Уральского и Тимано-Печерского бассейнов, Оренбургского и Актюбинского Приуралья, Прикаспийской впадины и других регионах страны.

Для детального изучения карбонатных резервуаров необходимо использование широкого спектра геолого-геофизической информации, большую роль в которой играет сейсморазведка. Она должна дать представление о внутреннем строении резервуара и изменении свойств коллектора в межскважинном пространстве. Однако фундаментальные физические свойства сейсмических волновых полей накладывают весьма жёсткие ограничения на разрешающую способность методов, опирающихся на использование отражённых волн. Поэтому, когда речь заходит о трещинных и трещинно-кавернозных типах коллекторов, стандартные сейсмические методы, основанные на использовании отраженных волн, не столь эффективны, как в классических терригенных. Отличительной особенностью карбонатных коллекторов является отсутствие резкой акустической границы на их кровле, что связано с диффузным характером пустот, образованных в процессе растворения и выщелачивания горных пород [Левянт и др., 2010].

Значительного расширения и углубления информации, получаемой с использованием сейсмических методов, удаётся добиться путём привлечения 
рассеянных/дифрагированных волн. Действительно, уже само по себе их присутствие говорит о наличии в среде сингулярных объектов, таких как разломы, трещины, скопления каверн и других. Следовательно, использование таких волн открывает возможность значительного повышения информативности и разрешающей способности сейсмических методов изучения внутреннего строения среды.

В настоящее время известны несколько подходов, ориентированных на использование рассеянной/дифрагированной составляющей полного волнового поля. Перечислим наиболее распространённые из них.

1) Изучение субвертикальных зон трещиноватости путём возбуждения и последующей регистрации в горных породах дуплексных волн и их использование для обнаружения субвертикальных границ [Твердохлебов, Птецов, 2006; Хромова, 2008]. К сожалению, область применения этого способа чрезвычайно узка и ограничена весьма частными случаями зон с протяжённой субвертикальной трещиноватостью, обусловленной тектоническими нарушениями.

2) Оптимальное суммирование сейсмической энергии вдоль дифракционных годографов. Здесь наиболее известны продукты Multifocusing компании Geomage [Berkovitch et al., 2009] и CRS (Common Reflection Surface) проф. Д.Гаевского из Института геофизики Гамбургского университета [Dell and Gajewski, 2011]. Успешность применения данных подходов во многом зависит от качества оценки параметров дифракционных годографов. К сожалению, на полевых данных добиться требуемого качества весьма проблематично даже для отражённых волн [Bakulin et al., 2020], а для рассеянных, по нашему мнению, практически невозможно, особенно для участков со сложной верхней частью.

3) Декомпозиция сейсмических данных на отражённую и рассеянную/дифрагированную составляющие. Отличительной особенностью этого подхода является выделение рассеянной/дифрагированной составляющей в пространстве данных. Наиболее заметные успехи здесь достигнуты в группе профессора С.Фомеля из Университета Техаса в Остине. Им предложена и реализована следующая схема, состоящая из двух основных шагов [Merzlikin et al., 2017]:

- $\quad$ Разделение отражения и рассеяния/дифракции в пространстве данных;

- Построение миграционных скоростей, оптимальных для изображения рассеивающих/дифрагирующих объектов.

Построения основаны на следующем предположении:

в области просуммированных данных регулярные отражения соответствуют сильным когерентным событиям с непрерывно изменяющимися наклонами.

Для того, чтобы подавить регулярные отражения здесь используется так называемый «Разрушитель Плоских Волн» или в оригинальном названии «Plane Wave Destructor» [Fomel, 2002]. Этот оператор оценивает непрерывно изменяющиеся локальные наклоны доминирующих сейсмических событий путём формирования предсказания каждой трассы в данных, исходя из соседних трасс. Далее минимизируется невязка между предсказанной и наблюдённой трассами с соблюдением ограничений на гладкость углов наклона и строится целевая функция, аналогичная дифференциальному семблансу (Differential Semblance). Наиболее трудная составляющая этого подхода, не всегда устойчиво реализуемая на практике, состоит в определении оптимального азимута, для которого строится «разрушитель плоских волн».

4) Модификация ядра миграционного преобразования Кирхгофа [Koren, Ravve, 2011; Ravve, Koren, 2011] наиболее близка, видимо, к предлагаемому в данной работе подходу построения дифракционных изображений с использованием Гауссовых пучков. Именно эта разработка авторов (Paradigm) легла в основу популярной системы обработки данных трёхмерной сейсморазведки, известной как EarthStudy 360. Заметим, что этот продукт также ориентирован на трассировку лучей из целевой области по направлению к системе возбуждения и регистрации и также работает в области углов. 
В данной работе мы представляем технологию специальной обработки данных трёхмерной сейсморазведки, ориентированную на выявление залежей углеводородов в карбонатных коллекторах и основанную на использовании рассеянных волн. Эти волны образуются на геологических неоднородностях, характерные размеры которых хотя бы в одном направлении существенно меньше длины сейсмических волн и чаще всего связанных с трещиноватостью и кавернозностью горных пород [Поздняков и Чеверда, 2005; Бондарев, 2007; Ланда 2013; Харахинов и Шлёнкин, 2015; Козяев и др. 2017; Петров и др. 2019].

В разработанной нами технологии построения трехмерных сейсмических изображений выделение рассеянных волн основано на использовании Гауссовых пучков. Гауссов пучок - это специальным образом построенное асимптотическое решение системы уравнений динамической теории упругости, сосредоточенное в узкой окрестности заранее выбранного луча [Бабич и Булдырев, 1991; Popov, 2002]. Построение изображения выполняется в фиксированной точке, из которой выпускается пара продольных лучей - один в направлении источников, а другой в направлении приемников (Error: Reference source not found). Построенные лучи полностью определяются заданной макромоделью. Затем для этих лучей строятся соответствующие им продольные Гауссовы пучки. Далее на апертурах приёмников и источников вычисляются следы построенных пучков, которые используются как веса суммирования исходных данных многократного перекрытия для построения изображения в выбранной точке. В результате, получается детальное трехмерное изображение резервуара в рассеянных волнах. Таким образом, строятся изображения с использованием РР-рассеянных волн. Заметим, что точно также могут быть построены и изображения в PS-волнах, то есть когда используются рассеянные S-волны. При этом нужно подчеркнуть, что ни для построения изображений в рассеянных PP ни в PS волнах не требуется выполнения предварительного разделения полного волнового поля на продольные и поперечные волны (см. [Кутовенко и др., 2010; Protasov et al., 2016, 2019]).

Основное внимание в данной работе мы уделяем верификации развитой методики построения изображений разномасштабных геологических объектов. Именно для этого мы создали цифровой двойник одного из лицензионных объектов ПАО НК Роснефть, основываясь на геологических и геофизических данных. Кроме того, для расширения возможностей тестирования мы добавили в этот двойник ряд специфических черт, таких как коридоры трещиноватости и зоны повышенной кавернозности. Для построенного цифрового объекта было выполнено численное моделирование и получены синтетические сейсмические волновые поля. Таким образом, мы получили возможность проведения полностью контролируемого численного эксперимента. Убедившись, что разработанные процедуры корректно восстанавливают строение цифровой модели, мы провели обработку и реальных данных, которая также дала результаты, не только вполне соответствующие ранее полученным с использованием других подходов, но и несущие дополнительную, весьма важную геологическую информацию.

\section{ПОСТРОЕНИЕ ЦИФРОВОГО ДВОЙНИКА ГЕОЛОГИЧЕСКОГО ОБЪЕКТА}

В качестве основы для создания трехмерной модели было выбрано одно из месторождений севера Восточной Сибири, где основным объектом является карбонатный резервуар рифейского возраста, содержащий залежи массивного типа, тектонически и литологически экранированные. Коллектор этого месторождения представляет собой сложную структуру с двумя видами пустотности - каверны и трещины, и характеризуется сильной гетерогенностью и анизотропией свойств. Также сочетает в себе низкую емкость (в среднем 1-2\%) и высокую проницаемость (до 4000 мД), в основном обеспечивающуюся за счёт естественной трещиноватости.

Начальный этап формирования модели заключался в построении её каркаса, то есть в описании границ раздела слоев, построенных в результате обработки и интерпретации 
данных трёхмерной сейсморазведки. Параметры упругой среды между этими границами определяются на основе геофизических исследований скважин.

Важной особенностью изучаемого лицензионного участка является наличие разломов, разбивающих резервуар на серию блоков с амплитудами смещения, достигающими сотен метров. Здесь необходимо подчеркнуть, что в настоящее время общепринятым становится понимание геологического разлома как сложного трёхмерного геологического объекта [Kolyukhin et al., 2017; Вишневский и др., 2017]. Поэтому мы рассматривали разломы как некоторые объемные геологические тела, состоящие из горных пород, деформированных в результате тектонических движений [Faulkner at al., 2010]. Основные характеристики такого движения определяются широким спектром параметров, среди которых тектонический режим, магнитуда смещения слоев, механические свойства окружающих горных пород и другие [Hardy and Finch, 2005; 2007].

Численное моделирование сложного нелинейного процесса формирования геологических разломов выполнялось методом дискретных элементов. Метод дискретных элементов предполагает представление изучаемой среды в виде набора «дискретных элементов/частиц» простой геометрической формы. В частности, в данной работе используются дискретные элементы в виде шаров различного радиуса, взаимодействующие друг с другом по определенному набору физических законов [Cheverda et al., 2019]. Так, при рассмотрении тектонических процессов одним из основных типов взаимодействия становится трение между элементами, которое определяет так называемый угол внутреннего трения горных пород. Дополнительно может рассматриваться момент вращения элементов и пр., однако на тектоническом уровне, связанные с ними эффекты незначительны [Hardy and Finch, 2005]. При этом, удобно разделять силы, определяющие нормальные и касательные взаимодействия.

Касательные силы, в частности, трение, в основном и определяют свойства среды на макроуровне [Duan et al., 2012]. В свою очередь, для описания внутреннего трения наиболее часто используется закон Кулона, в соответствие с которым статическое трение определяет взаимодействие между дискретными элементами/частицами до тех пор, пока оно не превысит некоторое пороговое значение, после которого уже определяющей величиной становится трение скольжения. Для большинства геоматериалов коэффициент статического трения равен 0.9, и именно это значение мы использовали в расчетах. Ещё одной важной величиной является коэффициент динамического трения. Как правило, он меняется от 0.0 до 0.4. Именно этот коэффициент определяет такой значимый параметр, как угол внутреннего трения. В данной работе использовался изменяющийся с глубиной коэффициент динамического трения, причем это изменение задавалось в интервале от 0.1 до 0.3.

Главная цель численного моделирования формирования разлома состоит в определении и анализе распределения деформаций в его окрестности, особенно для случая разлома со смещением. Для проведения моделирования выбирался параллелепипед с размерами 2000м х 2000м х 500м (Error: Reference source not found). Размер дискретных элементов (шары) варьировался от 2.5 до 15 метров. Модули жесткости брались равными 16 Гпа независимо от того, в каком слое они находились. Для учета изменчивости геомеханических свойств среды (слоев) изменялся коэффициент динамического трения в них, что влияло на интенсивность касательных сил. Для моделирования тектонических движений на берегах разломов задавались горизонтальные и вертикальные смещения в качестве граничных условий. На Error: Reference source not found приведено распределение деформаций в окрестности разлома с амплитудой сброса 100 м. и смещением в положительном направлении по Ү, равном 50 м.

Выполненные численные эксперименты позволили оценить распределение деформаций в окрестности разломов. Далее, следуя эмпирическому закону, описывающему связь изменчивости относительной объемной деформации с вариациями 
скоростей продольных волн [Botter et al., 2014], мы определяем вариации упругих параметров в окрестности разломов (рис.3).

Для моделирования внутренней структуры разломов использовались данные геофизических исследований в горизонтальной скважине, вскрывающей разлом на изучаемом месторождении (рис.4). Конечно, мы отдаём себе отчёт, что данных по одной скважине недостаточно для подробного описания тектонической брекчии. Однако заданные в скважине скорости продольных и поперечных волн, а также плотности позволили откалибровать параметры, использованные при геомеханическом моделировании, что обеспечило получение близкого к реалистичному описанию тектонической брекчии, заполняющей геологические разломы (рис.5).

Кроме разломов, исследуемый карбонатный резервуар содержит в различных пропорциях коридоры трещиноватости и каверны, являющиеся основной ёмкостью (каверны) и транспортными путями (трещины) флюида. Зоны трещиноватости мы вводили в виде двух разнонаправленных систем субвертикальных трещин, полученных путём статистического моделирования методом спектрального разложения случайных полей. Это позволило сгенерировать трещины длинной от 5 до 300 метров, образующих реалистичные коридоры трещиноватости. Дополнительно, в модель были добавлены интервалы интенсивного кавернообразования, регулярно встречающиеся на месторождении. Согласно керновым исследованиям, эти интервалы, по отношению к вмещающим породам, обладают повышенной пустотностью достигающей 15-20 \% и небольшими толщинами от одного до десяти метров. Для определения параметров этих зон кавернообразования мы провели статистический анализ десяти цифровых моделей керна, построенных методом рентгеновской компьютерной томографии [Bazaikin et al., 2017].

Подчеркнём, что при построении сейсмогеологической модели мы не стремимся описать каждую отдельную трещину, толщиной в несколько миллиметров. Вместо этого мы строим так называемые коридоры трещиноватости [Questiaux et al., 2010], представляющие скопление трещин, имеющих одну либо несколько выделенных ориентаций. Коридоры трещиноватости могут простираться на несколько сотен метров, иметь высоту в первые десятки метров и толщину в первые метры. При их построении в геологической модели используются как прямые наблюдения на обнажениях, так и данные скважинных измерений. В данной работе мы опирались на полученные ранее результаты (см. [Kolyukhin et al., 2017; Козяев и др., 2017; Петров и др., 2019]), описывающие строение подобных объектов на основе статистического анализа результатов натурных наблюдений, включая обнажения и данные наблюдения пластовым микросканером UIB.

На рис. 6 изображен общий вид каркаса построенной трёхмерной модели с разломами и другими мелкомасштабными неоднородностями. Каркас задаётся в виде совокупности отражающих границ, геологических разломов, коридоров трещиноватости и зон повышенной кавернозности. Для определения упругих свойств среды, заполняющей этот каркас, мы использовали результаты скоростного анализа, скважинные данные, данные лабораторных измерений кернового материала.

Таким образом, в результате проведённых исследований мы создали цифровой двойник изучаемого региона, предназначенный для проведения численного моделирования сейсмических волновых полей. Использование разномасштабных геологогеофизических данных позволило обеспечить максимально достоверное описание как отражённых, так и рассеянных/дифрагированных сейсмических волновых полей.

\section{ЧИСЛЕННОЕ МОДЕЛИРОВАНИЕ СЕЙСМИЧЕСКИХ ВОЛНОВЫХ ПОЛЕЙ}

На следующем шаге, по сути завершающим создание цифрового двойника изучаемого объекта, было выполнено конечно-разностное моделирование трёхмерных многокомпонентных данных многократного перекрытия. Подчеркнём ещё раз, что именно 
на этой основе открывается возможность детального анализа особенностей процессов формирования и распространения рассеянных волн, без знания которых невозможно развитие технологии реконструкции карбонатного резервуара. Кроме того, при этом становится возможным проведение полностью контролируемых численных экспериментов для верификации разработанных методов восстановления строения резервуаров на субсейсмическом масштабе для локализации скоплений трещин и каверны, Именно распределение таких микронеоднородностей обеспечивает выбор стратегии оптимальной разработки резервуаров в карбонатном окружении.

Однако существующие в настоящее время методы численного моделирования сейсмических волн для решения таких задач не всегда могут быть реализованы даже с использованием самых мощных на сегодня высокопроизводительных вычислительных систем. Дело в том, что, как правило, для этого используются явные конечно-разностные схемы, ориентированные на равномерные сетки с пространственным размером ячейки равным 0.1-0.2 доминирующей длины волны, что, как правило, составляет 5-10 метров, в то время как характерные размеры неоднородностей составляют 0.01-0.1 метров. Для моделирования взаимодействия сейсмических волновых полей с такими неоднородностями необходимо использовать шаг по пространству, сравнимый с их размерами. Однако использование шага в 0.05 метров во всей целевой области потребует колоссальных вычислительных ресурсов - терабайты оперативной памяти и терафлопы производительности.

Для того, чтобы избежать необходимости привлечения таких нереальных на сегодняшний день вычислительных мощностей нами был использован подход, использующий конечно-разностные схемы с локальным пространственно-временным измельчением сетки в областях скоплений мелкомасштабных неоднородностей [Костин и др., 2013; Kostin et al., 2015; Landa et al., 2018]. При этом используются сетки с меняющимися шагами по пространству для корректного представления различных составляющих модели: сравнительно крупный шаг - для описания трехмернонеоднородной вмещающей среды и гораздо более мелкий - внутри пласта-коллектора и разломных зон (Error: Reference source not found7). Вычисления организованы так, чтобы обеспечить равномерную загрузку вычислительных мощностей, производящих вычисления и на мелком и на крупном шаге. Данный подход существенно снижает требования к объемам оперативной памяти и количеству вычислительных процессов.

При проведении вычислений для построенной многомасштабной модели мы провели декомпозицию рассматриваемой модели на два класса:

- вмещающая среда, содержащая отражающие граница и плавно изменяющуюся среду между ними;

- скопления мелкомасштабных неоднородностей, такие как разломы, заполненные тектонической брекчией, скопления каверн и трещин.

Во вмещающей среде использовался шаг сетки равный пяти метрам, а вне неё сетка с шагом 0.5 м, что и обеспечило возможность довольно точно описать изменчивость упругих свойств среды.

Проведение полномасштабного численного моделирования осуществлялось для модели, заполняющей параллелепипед 8 км х 10 км х 6 км, а система наблюдения располагалась на поверхности z=0 внутри прямоугольника 8 км х 10 км.

Она представляла собой систему многократного перекрытия с фиксированной системой трехкомпонентных приемников с шагом 25 метров. Расстояние между линиями приема сигнала принято 300 метров. В качестве возбуждения сигнала взяты источники типа центра расширения (взрыв) с шагом 50 метров и расстоянием между линиями на 300 метров. Это позволило обеспечить кратность перекрытия равной 100 в подавляющем объёме области наблюдения (рис.8). В качестве сигнала в источнике использовался импульс Рикера с доминирующей частотой 40 Гц. На рис. 9 мы приводим сейсмограмму для центральной линии и амплитудно-частотную характеристику. 


\section{ПОСТРОЕНИЕ ВОЛНОВЫХ ИЗОБРАЖЕНИЙ В РАССЕЯННЫХ ВОЛНАХ}

На заключительном этапе созданная цифровая модель реального месторождения и вычисленное для нее сейсмическое волновое поле использовались сначала для верификации разработанной технологии построения изображения резервуара в рассеянных волнах методом Гауссовых пучков, а затем и для обработки данных полевых наблюдений. В отличие от разработанного и использованного ранее метода построения изображений мелкомасштабных объектов с использованием глубинной скоростной модели [Protasov, Gadylshin, Tcheverda and Pravduhin, 2019; Protasov, Tcheverda and Pravduhin, 2019], в данной публикации мы используем временную скоростную модель. Связано это с тем, что в настоящее время для изучаемого объекта трёхмерная глубинная скоростная модель не построена. Поэтому для начала опишем модификацию разработанного ранее алгоритма построения изображений в рассеянных волнах с использованием Гауссовых пучков с использованием глубинной скоростной модели. Для этого кратко остановимся на условии построения изображений (Image Condition в англоязычной литературе) для PPрассеяния, хотя точно также может использоваться и PS-рассеяние.

В последующих рассмотрениях, считается, что изучаемая среда представляется в виде суперпозиции двух компонент: вмещающей среды с плавно меняющимися упругими параметрами $\lambda_{0}(x), \mu_{0}(x), \rho_{0}(x)$ и её локальных возмущений $\lambda_{1}(x), \mu_{1}(x), \rho_{1}(x)$. Далее, на свободной поверхности предполагается известным рассеянное волновое поле $\varphi\left(x_{r}, y_{r} ; x_{s}, y_{s} ; \omega\right)$, возникающее в результате взаимодействия падающей волны со скоплениями мелкомасштабных неоднородностей. Здесь $\left(x_{s}, y_{s}\right)$ координаты источника, $\left(x_{r}, y_{r}\right)$ - приёмника, $\omega$ - временная частота. Теперь из внутренней точки области $x$ трассируется два Гауссовых пучка в направление системы наблюдения на свободной поверхности (рис. 1):

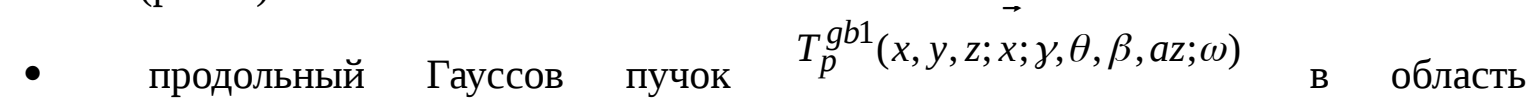
расположения приёмников;

$$
\text { - } \quad \text { скалярный Гауссов пучок } T_{p}^{g b 2}(x, y, z ; \bar{x} ; \gamma, \theta, \beta, a z ; \omega) \text { для продольной }
$$
скорости распространения в область расположения источников.

Для каждого из них вычисляются проекции при $z=0$ и эти проекции используются как веса суммирования при вычислении так называемого селективного изображения во внутренней точке $x$ :

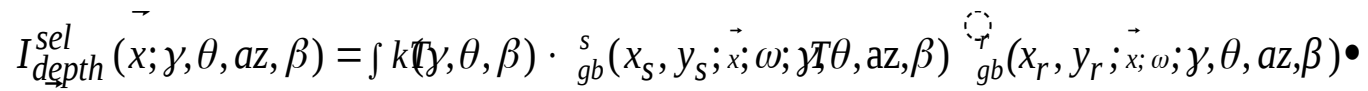

$$
\begin{aligned}
& \text { - } \varphi\left(x_{r}, y_{r} ; x_{S}, y_{s} ; \omega\right) d \omega d x_{s} d y_{s} d x_{r} d y_{r}
\end{aligned}
$$

Здесь $k(\gamma, \theta, \beta)$ некоторая нормирующая функция [Protasov et al., 2019]. Как показал проведённый в работах [Protasov et al., 2016; Протасов и др., 2017], асимптотический анализ имеет место следующее представление полученного в (1) выражения:

$$
I_{d e p t h}(x ; \theta, a z, \beta)=\underset{X_{p a r}(x)}{\iiint \int_{R^{3}} \exp \{i p x\} F(\omega(p)) d p} \exp \{-i p y\} f(y ; a z ; \beta) d y
$$

где

$$
\overrightarrow{f(x ; a z, \beta)}=\lambda_{1}+2 \mu_{1} \cos ^{2}(2 \beta)+v_{0 p}^{2} \rho_{1} \cos (2 \beta)
$$


Обратное преобразование Фурье в формуле (2) выполняется не по всему пространству, а по так называемому множеству частичного восстановления, которое определяется шириной частотного диапазона и геометрией используемой системы наблюдения (рис. 11):

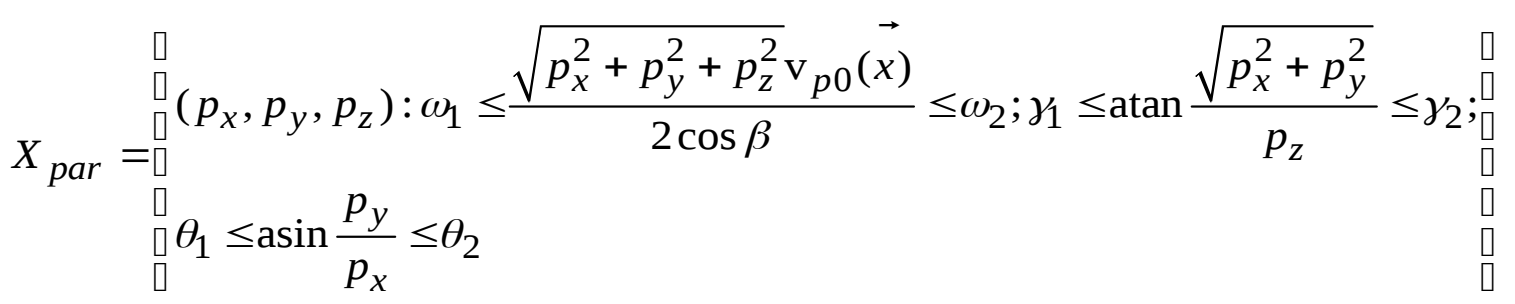

Это позволяет получать изображение не всего объекта, а только той его части, спектр которой попадает в это множество, так называемые селективные изображения. Таким образом, используя различные множества частичного восстановления мы будем получать отображение различных составляющих изучаемых геологических объектов. Отметим, в частности, что точечные возмущения обладают чрезвычайно широким пространственным спектром и, следовательно, будут присутствовать практически на всех селективных изображениях (см. [Поздняков и Чеверда, 2005; Protasov et al., 2016]).

К сожалению, глубинная скоростная модель известна далеко не всегда. В частности, для изучаемого лицензионного участка она до сих пор не построена. Поэтому для построения изображений в рассеянных волнах мы использовали модель средних скоростей во временном масштабе, построенную в результате обработки данных многократного перекрытия по методу ОГТ/ОСТ. Естественно, что и изложенный выше алгоритм, определяемый соотношением (1) был модифицирован для моделей такого типа. Напомним, что в рассматриваемой постановке оба Гауссовых пучка идут снизу-вверх, но в модели средних скоростей среда выше точки построения изображения предполагается однородной. Следовательно, Гауссовы задаются аналитической формулой, что позволяет выполнить интегрирование по частоте $\omega$ в явном виде. В итоге получим:

$$
\begin{aligned}
& I_{d e p t h}^{s e l}(x ; \gamma, \theta, a z, \beta)=\int k(\bar{\gamma}, \theta, \beta) \cdot{ }_{g \underline{s}}^{s}\left(x_{s}, y_{s} ; \vec{x} ; t=\tau_{g b s}\left(x_{s}\right) ; \gamma, \theta, a z, \beta\right) \\
& \overrightarrow{T_{g b}^{r}}\left(x_{r}, y_{r} ; \vec{x} ; t=\tau_{g b r}\left(x_{r}\right) ; \gamma, \theta, a z, \beta\right) \varphi\left(x_{r}, y_{r} ; x_{s}, y_{s} ; t=\tau_{g b s}\left(x_{s}\right)+\tau_{g b r}\left(x_{r}\right) ;\right) d x_{s} d y_{s} d x_{r} d y_{r} \text {, } \\
& \text { где времена } \tau_{g b s}\left(x_{s}\right) \text { и } \tau_{g b r}\left(x_{r}\right) \text { вычисляются вдоль отрезков прямых, }
\end{aligned}
$$
соединяющих точку построения изображений и точки расположения источников и приёмников соответственно.

Таким образом, для построения изображения во временной скоростной модели нам нужно взять (4) для текущей скоростной модели $V_{0 p}$ в точке $x=\left(x_{i}, y_{i}, z_{i}=0.5 t_{i} V_{0 p}\right)$ :

$$
I_{\text {time }}^{\text {sel }}\left(x_{i}, y_{i}, t_{i} ; \gamma, \theta, a z, \beta\right)=I_{\text {depth }}^{\text {sel }}\left(x_{i}, y_{i}, z_{i}=0.5 t_{i} V_{o p} ; \gamma, \theta, a z, \beta\right)
$$

Как правило, построение изображений в рассеянных волнах выполняется после того, как проведена стандартная обработка по методу отражённых волн, то есть когда уже известна не только скоростная модель во временной области, но и получены поверхности, порождающие регулярные отражённые волны. Другими словами, когда уже известны геометрические характеристики этих поверхностей и, следовательно, становится возможным выбор структурных углов Гауссовых пучков, не совпадающих со структурными углами отражающих поверхностей. Это и позволяет получить изображения, во многом свободные от наличия на них регулярных отражающих границ, но содержащие рассеивающие объекты.

На рис. 12 слева приведены разломы и мелкомасштабная составляющая исходной геологической модели (коридоры трещиноватости и скопления каверн), а справа - 
построенное изображение в рассеянных волнах. Как видно, и разломы и все мелкомасштабные объекты восстановлены корректно и полностью соответствуют модели. Трехмерные изображения модельных неоднородных зон (разломы, трещины, каверны) и их изображение в рассеянных волнах хорошо сопоставляются. Их амплитуды (интенсивность) примерно равны, как и пространственная разрешённость всех объектов, что полностью соответствует полученным теоретическим результатам.

\section{ОБРАБОТКА ДАННЫХ ПОЛЕВЫХ НАБЛЮДЕНИЙ}

Разработанный метод построения изображений применяется для обработки полевых данных на ряде месторождений Восточной Сибири. В первую очередь, это месторождения Юрубчено-Тохомской зоны нефтегазонакопления, расположенные в пределах Лено-Тунгусской нефтегазоносной провинции, в районе Камовского свода Байкитской антеклизы, в административном отношении расположены в Красноярском крае. Это уникальные по своим размерам месторождения разломно-блокового строения, простирающиеся на несколько десятков тысяч километров. Основной промышленный интерес представляют преимущественно доломитизированные отложения рифейского возраста, с которыми связаны наибольшие объёмы ресурсов углеводородов. Согласно принятой в настоящее время модели рифейский коллектор представлен низкопроницаемыми породами, проницаемость которых обеспечивается совокупностью сообщающихся макро- и микротрещин и приуроченных к ним каверн и пустот выщелачивания. Диффузный характер распространения таких пустот значительно затрудняет изучение коллекторских свойств по стандартным методам сейсморазведки, базирующихся на отражённых волнах, но, в то же время, является благоприятной средой для применения технологии выделения рассеянных волн методом Гауссовых пучков.

Применение технологии на одном из исследуемых участков позволило получить детальное изображение целевого рифейского разреза в рассеянных волнах. На полученном изображении удалось локализовать зону повышенной энергии, связанную, вероятно, с ранее пропущенным тектоническим нарушением, слабо различимом на классическом изображении отражённых волн (рис. 13). Факт существования разлома подтверждается результатами бурения двух скважин, вскрывших разновозрастные толщи. Полученные результаты позволят в значительной мере уточнить структурно-тектонический план месторождения и снизить потенциальные геологические риски.

На другом участке, где применялась технология, уже широко велась разработка месторождения, что открыло новую возможность для технологии - использование её при сопровождении эксплуатационного бурения. Свойства трещинно-кавернового рифейского коллектора сложно прогнозировать из-за их гетерогенности и анизотропии. Продуктивность в основном связана с суммарной интенсивностью и раскрытостью вскрываемой скважиной естественной трещиноватости. Так, при бурении одной из горизонтальных скважин было зафиксировано интенсивное поглощение бурового раствора, связанное с трещиноватостью. Проведённые скважинные исследования пластовым микросканером (UBI) подтвердили данный факт, выявив сильную трещиноватость. Анализ куба рассеянных волн, полученного методом Гауссовых пучков, показывает хорошее соответствие между аномалиями в волновом поле с максимумами кривых плотности трещин по ГИС и кривыми поглощения бурового раствора. Достаточно контрастно проявляется и разлом на нижнем рисунке, чего нельзя сказать о разрезе куба отражённых волн, где вышеперечисленные особенности не отмечаются (рис.14). Данный результат предполагает расширение возможности применения технологии для мониторинга бурения эксплуатационных скважин. Высокая разрешающая способность технологии позволит применять её на стадии сопровождения бурения: для проводки горизонтального ствола в зоны улучшенных коллекторских свойств, что позволит снизить риски бурения. 


\section{ЗАКЛЮЧЕНИЕ}

Современный уровень развития технологии обработки сейсмических данных и интерпретации полученных результатов предполагает проведение тщательной апробации новых разработок. Естественно, что на начальной стадии апробация должна производиться на хорошо известных объектах. Наилучшим образом для этого подходят синтетические модели, детально описывающие реальные геологические объекты. Действительно, при этом на всех этапах обработки данных и интерпретации полученных результатов удаётся обеспечить полный контроль за ходом восстановления изучаемых геологических объектов. На этой основе открывается возможность для определения оптимальной системы возбуждения и регистрации данных и понять границы применимости предлагаемого метода для решения конкретной задачи.

Заметим, что такой подход уже в течение довольно длительного времени развивается в созданной при SEG (Society of Exploration Geophysicists) корпорацией SEG Advanced Modelling Corporation ( https://seg.org/News-Resources/Research-and-Data/SEAM ), которая совместно с геологами крупнейших нефтяных компаний создаёт типичные синтетические модели для решения различных геологических задач, например, таких как:

- построение подсолевых изображений в третичных бассейнах (https://seg.org/NewsResources/SEG-Advanced-Modeling-SEAM/SEAM-Projects/Phase-I-Subsalt, 2011);

- вызовы наземной сейсмики, в (https://seg.org/SEAM/Phase2, 2018), включая трещиноватые резервуары, пустынные области с карстовыми приповерхностными включениями, предгорья со сложной топографией свободной поверхности;

- прогноз пластового давления на основе сейсмических изображений (https://seg.org/News-Resources/SEG-Advanced-Modeling-SEAM/SEAM-

Projects/Pressure-Prediction , 2017)

и ряд других.

В данной работе мы сосредоточились на построении синтетической модели, представляющей собой цифровой двойник некоторого геологического объекта, но добавили в него дополнительные элементы, изучение отображений которых в волновых сейсмических полях представляют и самостоятельный интерес - коридоры трещиноватости и зоны повышенной кавернозности. Разработанная технология построения трехмерных сейсмических изображений рассеянных волн методом Гауссовых пучков апробировалась именно на такой синтетической реалистичной трёхмерной карбонатного месторождения Восточной Сибири. Полученные при этом результаты продемонстрировал существенное повышение точности локализации тектонических нарушений и зоны улучшенных фильтрационно-емкостных свойств трещиноватокавернозных коллекторов. Мы рассчитываем, что использование такой технологии позволит заметно повысить успешность геологического моделирования и последующего разведочного и эксплуатационного бурения сложно построенных резервуаров.

\section{БЛАГОДАРНОСТИ}

Мы благодарны анонимному рецензенту и А.А.Мерецкому за внимательный анализ представленных нами результатов и их конструктивные замечания, которые позволили заметно улучшить качество статьи. Мы также благодарны геологам ООО РН КрасноярскНИПИнефть за их помощь при построении синтетической модели. 


\section{СПИСОК ЛИТЕРАТУРЫ}

1. Бабич В.М., Булдырев В.С. Асимптотические методы в дифракции коротких волн. // Москва, Наука, 1972.

2. Бондарев В.И. Сейсморазведка // Екатеринбург: УрГГУ. - 2007. - С. 704.

3. Вишневский Д.М., Колюхин Д.Р., Лисица В.В., Протасов М.И., Решетова Г.В., Ку Д., Тверангер Я. Корреляционный анализ статистической фациальной модели разломной зоны // Доклады РАН. - 2017. - т.473. - №6. - 719 - 723.

4. Козяев А.А., Мерзликина А.С., Петров Д.А., Шиликов В.В., Тузовский А.А., Сорокин А.С., Кутукова Н.М., Мельников Р.С., Чеверда В.А. Выявление зон с улучшенными фильтрационно-ёмкостными свойствами в карбонатном каверновотрещинном коллекторе по рассеянной составляющей сейсмического волнового поля // Нефтяное хозяйство. - 2017.- №11. - С. 20-25.

5. Колюхин Д.Р., М.И. Протасов, Статистическое моделирование дискретной системы трещин с использованием сейсмических изображений // Вычислительные методы и программирование. - 2018. - Т19. - С. 270-281.

6. Костин В.И., Лисица В.В., Решетова Г.В., Чеверда В.А. Локальное пространственно-временное измельчение сеток для конечно-разностного моделирования упругих волн в трёхмерно-неоднородных разномасштабных средах // СибЖВМ. - 2013. №1. $-45-55$.

7. Кутовенко М.П., Протасов М.И., Чеверда В.А. Использование Гауссовых пучков для построения сейсмических изображений в истинных амплитудах по многокомпонентным данным // Технологии сейсморазведки. - 2010. - №4. - 3 - 13.

8. Ланда Е.И. 2013. Роль дифракционной компоненты волнового поля при построении сейсмических изображений // Технологии сейсморазведки. - 2013. - № 1. - С. $5-31$.

9. Левянт В.Б. и др. Методические рекомендации по использованию данных сейсморазведки для подсчета запасов углеводородов в условиях карбонатных пород с пористостью трещинно-кавернового типа / В.Б. Левянт, И.Ю. Хромова, Е.А. Козлов, И.Н.Керусов, Д.Е.Кащеев, В.В.Колесов, Н.Я.Мармалвский // Москва: ЦГЭ. - 2010. - С. 250.

10. Петров Д.А., Мельник А.А., Шиликов В.В., Тузовский А.А., Мельников Р.С., волянская В.В., Чеверда В.А., Протасов М.И. Выявление трещиновато-кавернозных коллекторов на основе интерпретации сейсмических рассеянных волн методом гауссовых пучков // Нефтяное хозяйство. - 2019. - №1. - С. 6-10.

11. Поздняков В.А., Чеверда В.А. Фокусирующие преобразования сейсмических данных для площадных стационарных систем // Геология и геофизика. - 2005. - №3. - 328 $-338$.

12. Протасов М.И., Чеверда В.А., Правдухин А.П., Исаков Н.Г. Трехмерная анизотропная миграция данных ЗД сейсморазведки на основе гауссовых пучков // Технологии сейсморазведки. - 2017. - № 1. - С. 35-47.

13. Рытов С.М., Кравцов Ю.А., Татарский В.И. Введение в статистическую радиофизику. ч. II. Случайные поля. Москва, Наука, 463 с., 1978

14. Твердохлебов Д.Н., Птецов Р.С. Новоые атрибуты анализа тектонических нарушений для создания детальной сейсмогеологической модели резервуаров // Технологии сейсморазведки. - 2006. - №4. - с. 47 - 50.

15. Харахинов В.В., Шленкин С.И. Трещинные резервуары нефти и газа. // Москва: Научный мир. - 2015. - С. 284.

16. Хромова И.Ю. Миграция дуплексных волн - метод картирования трещиноватых зон тектонического генезиса // Геология нефти и газа. - 2008. - №3. - 37 47.

17. Bakulin, I. Silvestrov, M. Dmitriev, D. Neklyudov, M. Protasov, K. Gadylshin, and V. Dolgov, Nonlinear beamforming for enhancement of 3D prestack land seismic data // 
Geophysics. - 2020. - Vol. 85(3). - p. V283-V296.

18. Bazaikin Y., Gurevich B., Iglauer S., Lebedev M., Khachkova T., Lisitsa V., Reshetova G. Effect of CT Image Size and Resolution on the Accuracy of Rock Property Estimates // Journal of Geophysical Research: Solid Earth. - 2017. - v.122 (5). - 3645 - 3647.

19. Berkovitch A., Belfer I., Hassin Y., Landa E. Diffraction imaging by multifocusing // Geophysics. - 2009 - v.74(6). - WCA75 - WCA81

20. C. Botter, N.Cardozo, S.Hardy, I.Lecomte, F.Escalona. From mechanical modeling to seismic imaging of faults: A synthetic workflow to study the impact of faults on seismic // Marine and Petroleum Geology. - 2014. - v. 57. - P. 187-207.

21. Cheverda V., Lisitsa V., Protasov M., Reshetova G., Glinsky B., Cheynykh I., Merzlikina A., Volyanskaya V., Petrov D., Melnik A., Shilikov V. Digital twins of multiscale heterogeneous geological objects: 3D simulation and seismic imaging of faults, fractures and caves // Supercomputing technologies in Mathematical modelling. Jornal of Physics: Conference Series. - 2019. - v. $1392-012051$.

22. Dell S., Gajewski D. Common-reflection-surface based workflow for diffraction imaging // Geophysics. - 2011. - v.76. - S187 - S195.

23. Duan K., Kwok C.Y., Ma X. DEM simulations of sandstone under true triaxial compressive tests // Acta Geotechnica. - 2017. - № 12(3). - P. 495 - 510.

24. $\quad$ Faulkner D.R., Jackson A.L., Lunn R.J., Schlische R.W., Shipton Z.K., Wibberley Z.K., Withjack M.O. A review of recent developments concerning the structure, mechanics and fluid flow properties of fault zones // Journal of Structural Geology. - 2010. - v. 32. - P. 15571575.

25. Fomel S. Application of plane-wave destruction filter // Geophysics. - 2002. - v. 67. $-1946-1960$.

26. Hardy S., Finch E. Discrete-element modelling of detachment folding // Basin Research. - 2005. - V. 17. - N. 4. - P. 507-520.

27. Hardy S., Finch E. Mechanical stratigraphy and the transition from trishear to kink-band fault-propagation fold forms above blind basement thrust faults: A discrete-element study // Marine and Petroleum Geology. - 2007. - V. 24. - P. 75-90.

28. Kolyukhin D.R., Lisitsa V.V., Protasov M.I., Qu D., Reshetova G.V., Tveranger J., Tcheverda V.A., Vishnevsky D.M. Seismic imaging and statistical analysis of fault facies models // Interpretation. - 2017. - № 5(4). - SP71 - SP82.

29. Koren Z., Ravve I. Full-azimuth subsurface angle domain wavefield decomposition and imaging. Part 1: Directional and reflection image gathers.

30. Kostin V.I., Lisitsa V.V., Reshetova G.V., Tcheverda V.A. Local time-space mesh refinement for simulation of elastic wave propagation in multi-scale media // Journal of computational physics. - 2015. - v.281. - 669-689.

31. Landa E., Reshetova G., Tcheverda V. Modeling and Imaging of Multiscale Geological Media: Exploding Reflectors Revisited // Geosciences. - 2018. - v.8 (12). - 486.

32. Merzlikin D., Meckel T.A., Fomel S., Sripanich Y. Diffraction imaging of highresolution 3D P-cable data from the gulf of Mexico using azimuthal plane-wave destruction // First Break. - 2017. - 35. - 41.

33. Characterization of Fractured Reservoirs // Schlumberger. - 2007. https://www.slb.com/-/media/files/theme/brochure/cb-characterization-09os0003.ashx

34. Protasov M.I., Reshetova G.V., Tcheverda V.A. Fracture detection by Gaussian beam imaging of seismic data and image spectrum analysis // Geophysical prospecting. - 2016 v. $64(1) .-68-82$.

35. Protasov M.I., Gadylshin K.G., Tcheverda V.A., Pravduhin A.P. 3D diffraction imaging of fault and fracture zones via image spectral decomposition of partial images. // Geophysical prospecting. - 2019 - v.67(5). - 1256-1270.

36. Protasov M.I., Tcheverda V.A., Pravduhin A.P. 3D true-amplitude anisotropic elastic Gaussian beam depth migration of 3D irregular data // Journal of seismic exploration. - 
2019 - v. 28(2). - $121-146$.

37. Questiaux J.-M., Gary D. Couples G.D. and Ruby N. Fractured reservoirs with fracture corridors // Geophysical Prospecting. - 2010. - v. 58. - 279 - 295.

38. Ravve I., Koren Z. Full-azimuth subsurface angle domain wavefield decomposition and imaging: part2 - Local angle domain // Geophysics. - 2011. - 76(2). - S51 S64. 
Подписи к рисунками в статье «Реконструкция строения реалистичной трехмерной неоднородной среды на основе обработки рассеянных волн методом Гауссовых пучков»

Рисунок 1. Схема построения трехмерных изображений рассеянных волн методом Гауссовых пучков.

Рисунок 2. Распределение объемных деформаций в окрестности разлома: общий вид и сечения.

Рисунок 3. Зависимость скорости продольных волн от объёмной деформации.

Рисунок 4. Поведение скорости распространения сейсмических волн (слева) и плотности (справа) вдоль ствола горизонтальной скважины. Зона разлома соответствует расстояниям 3370 м - 3380 м.

Рисунок 5. Вариации упругих параметров тектонической брекчии, заполняющей разломы.

Рисунок 6. Каркас сейсмогеологической модели (цифрового двойника геологического объекта). Полутоновые изображения соответствуют регулярным отражающим поверхностям.

Рисунок 7. Декомпозиция полной модели на две составляющие и их загрузка на различные вычислительные мощности.

Рисунок 8. Распределение кратности перекрытия.

Рисунок 9. Центральная сейсмограмма и её амплитудно-частотная характеристика.

Рисунок 10. Геометрия пары пучков: $\beta$ угол раствора центральных лучей; $\theta$ и $\gamma$ структурные углы биссектрисы угла, определяемого парой центральных лучей; az азимут плоскости, определяемой парой центральных лучей по отношению к оси X.

Рисунок 11. Множество частичного восстановления в спектральной области.

Рисунок 12. Слева: разломы и мелкомасштабная составляющая исходной модели. Справа: изображение всей модели в рассеянных волнах.

Рисунок 13. Разрез мигрированного куба отраженных волн (вверху) и разрез куба энергии рассеянных волн полученный методом Гауссовых пучков (внизу)

Рисунок 1 Разрез мигрированного куба отраженных волн вдоль эксплуатационной скважины (вверху) и разрез куба энергии рассеянных волн полученный методом Гауссовых пучков (внизу) 


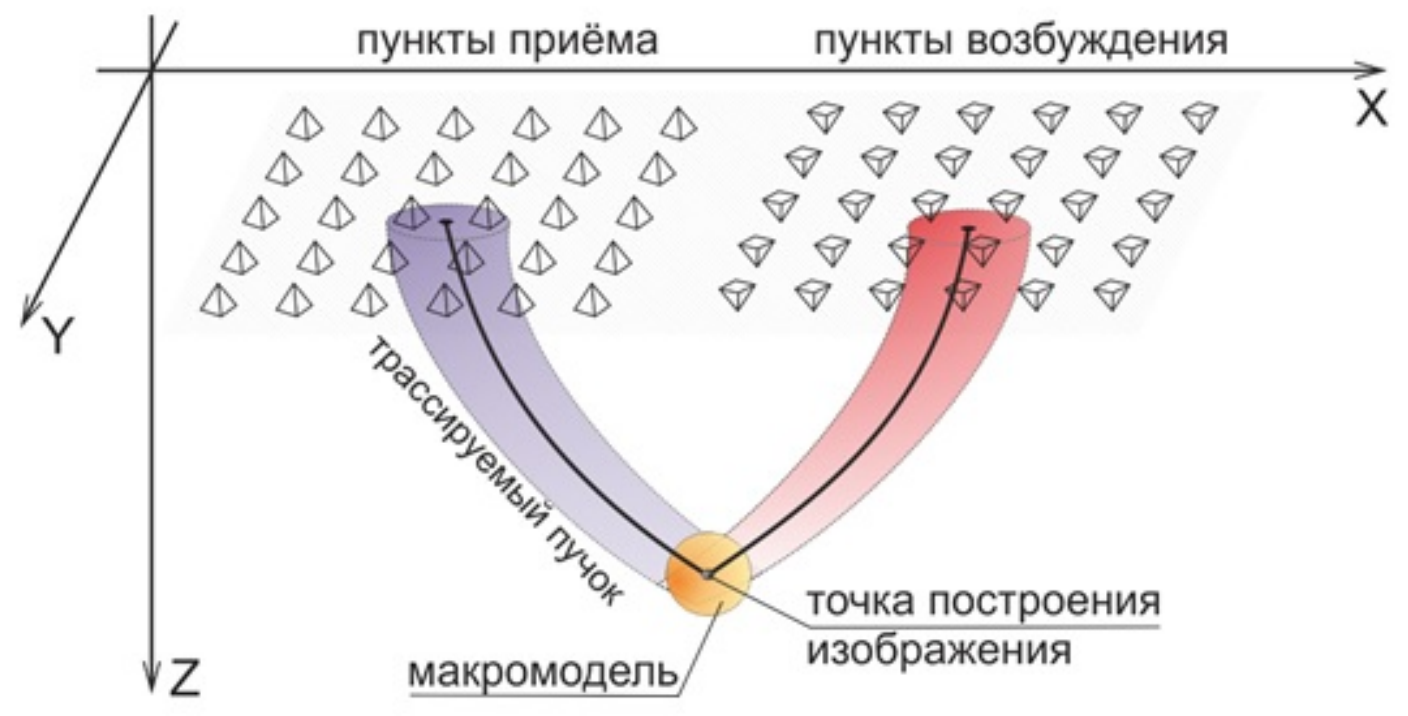




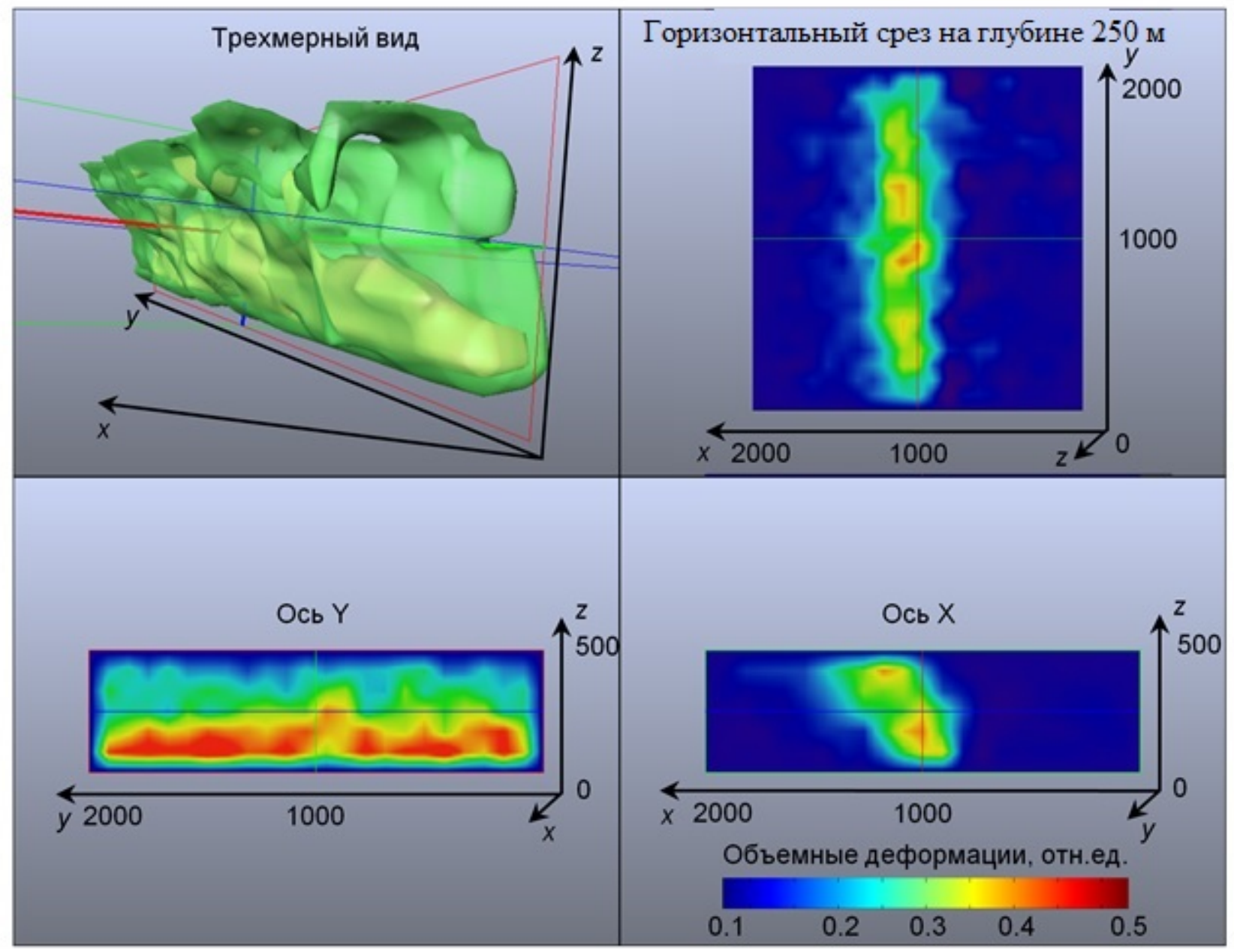




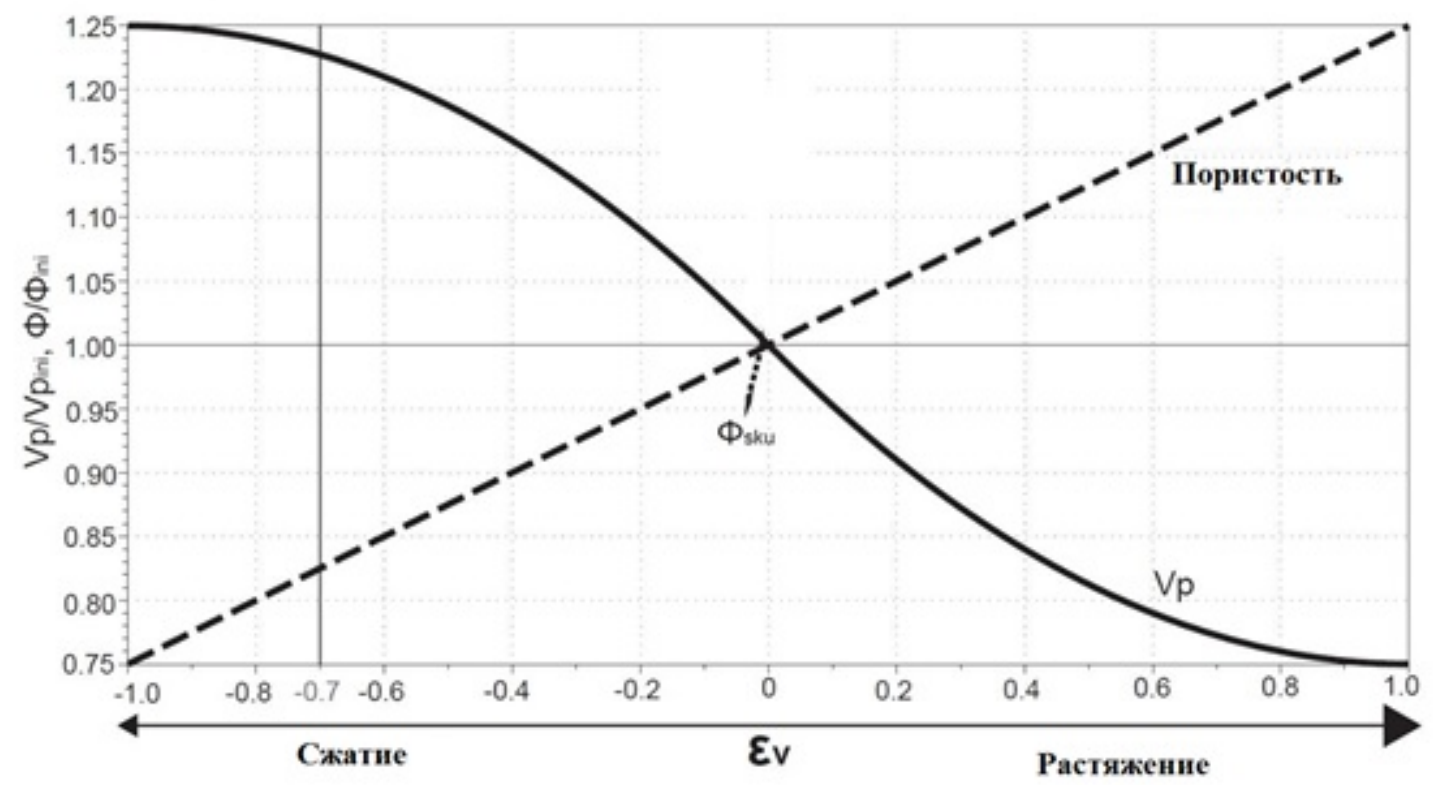




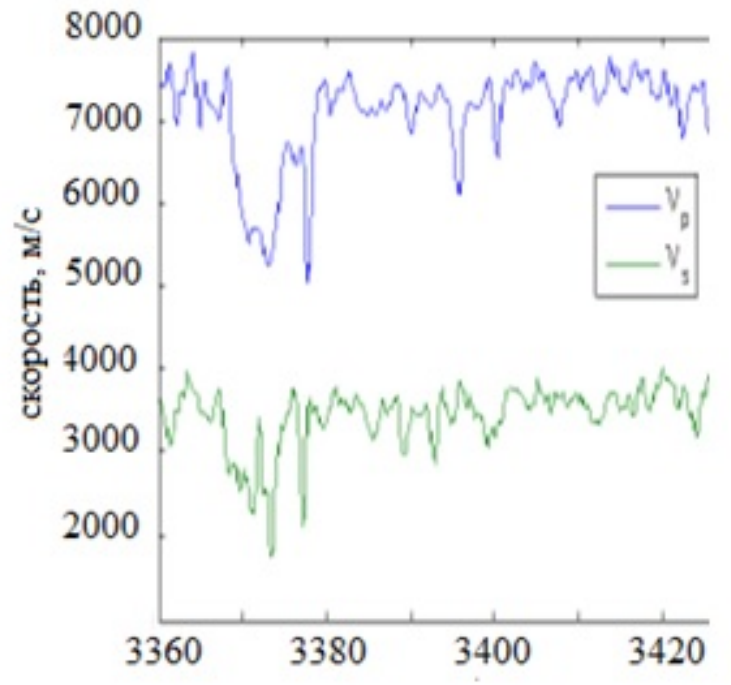

a)

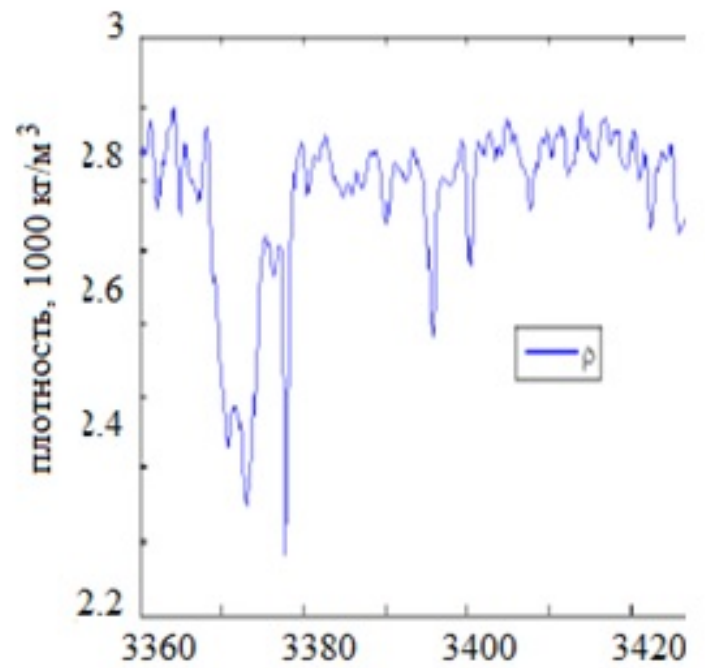

6) 

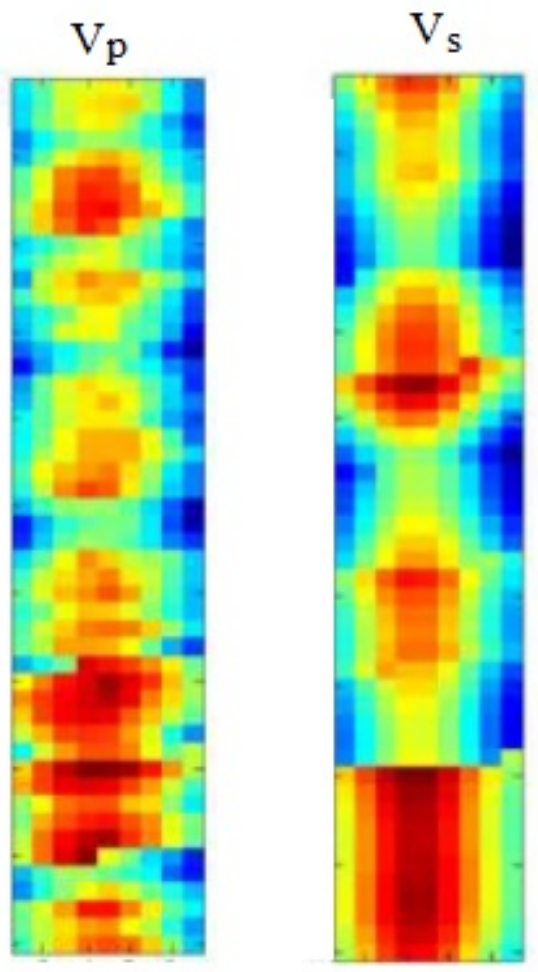

Density

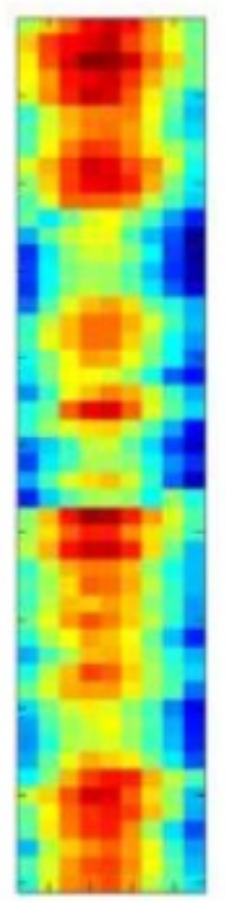




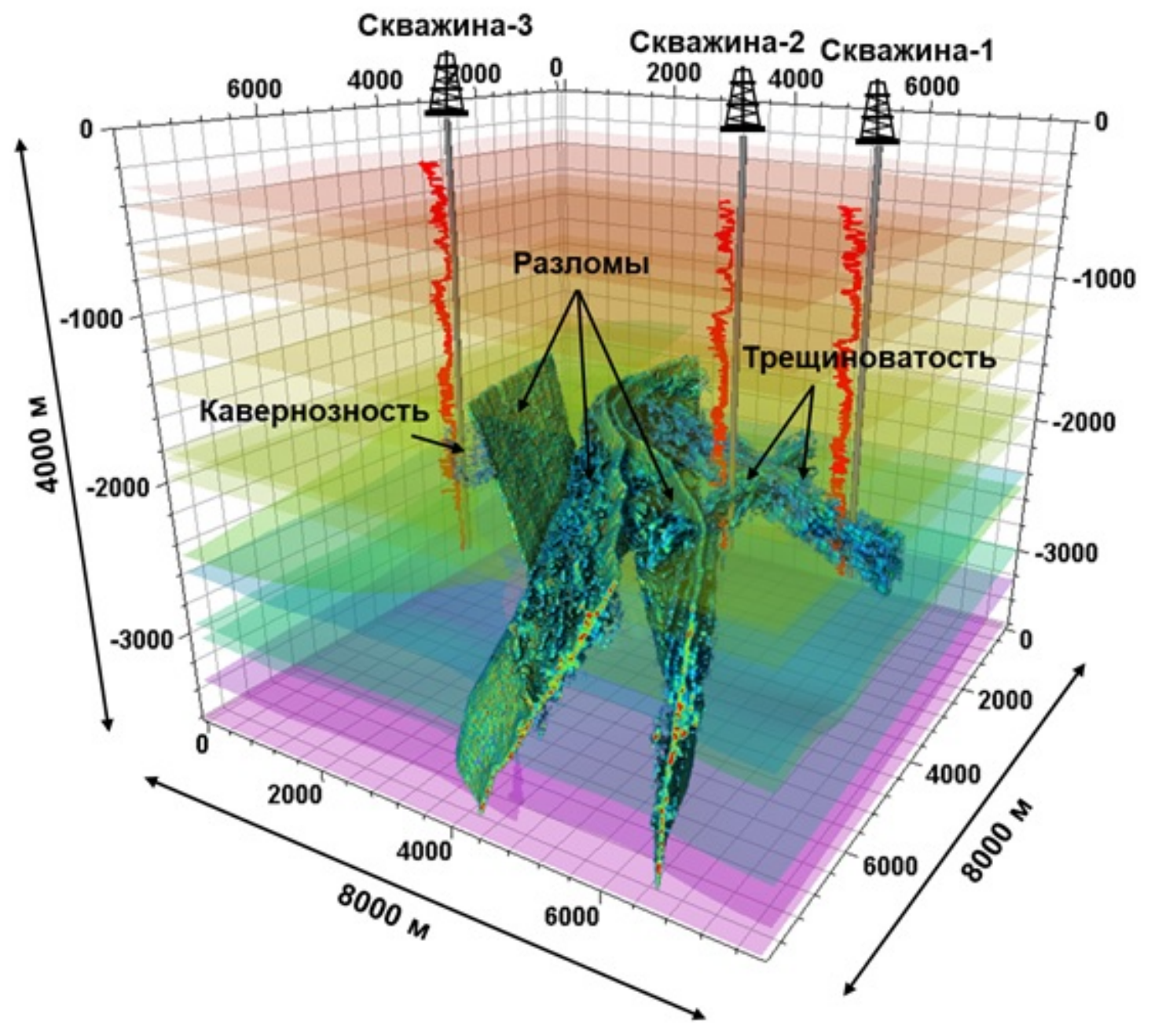




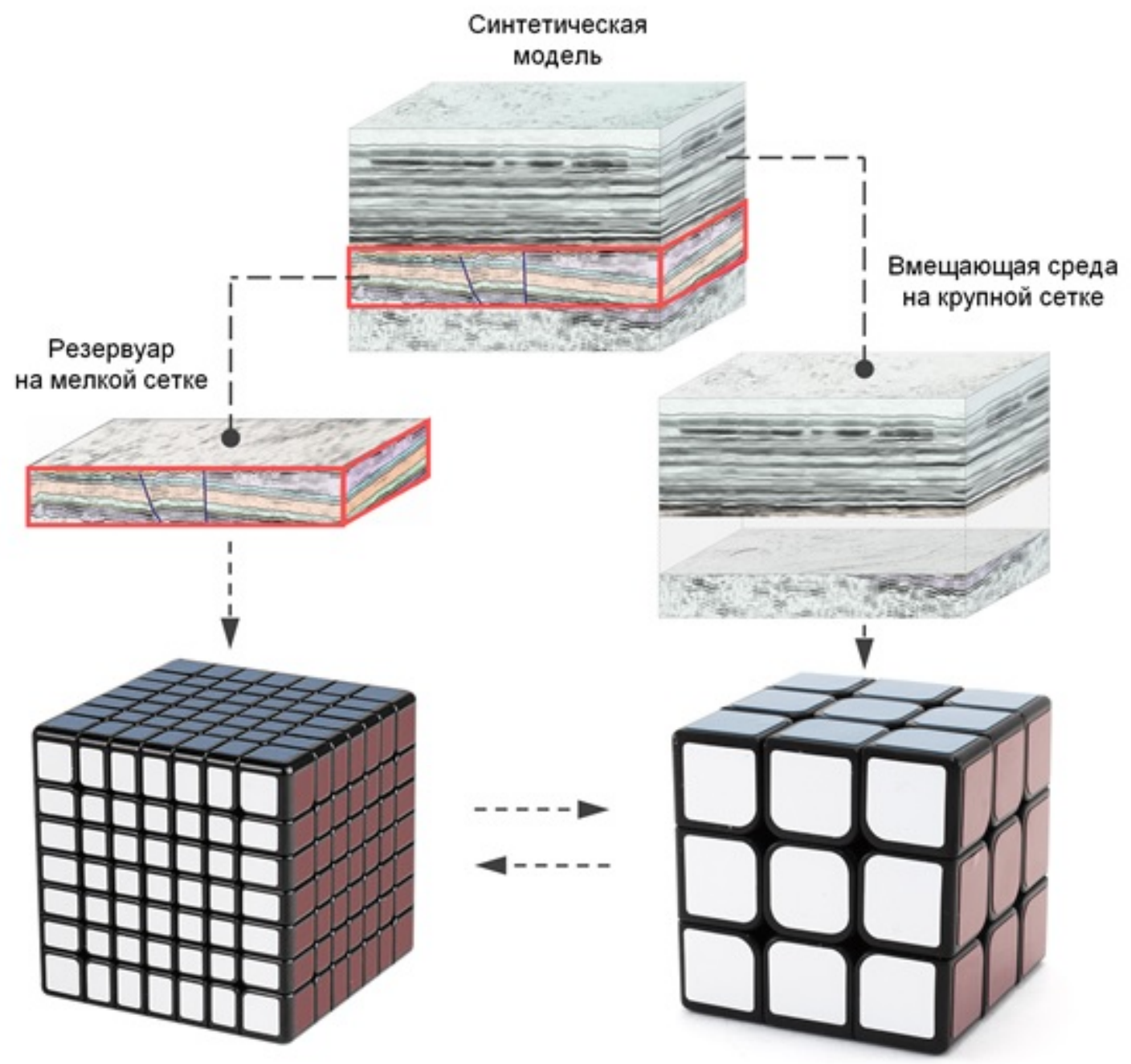



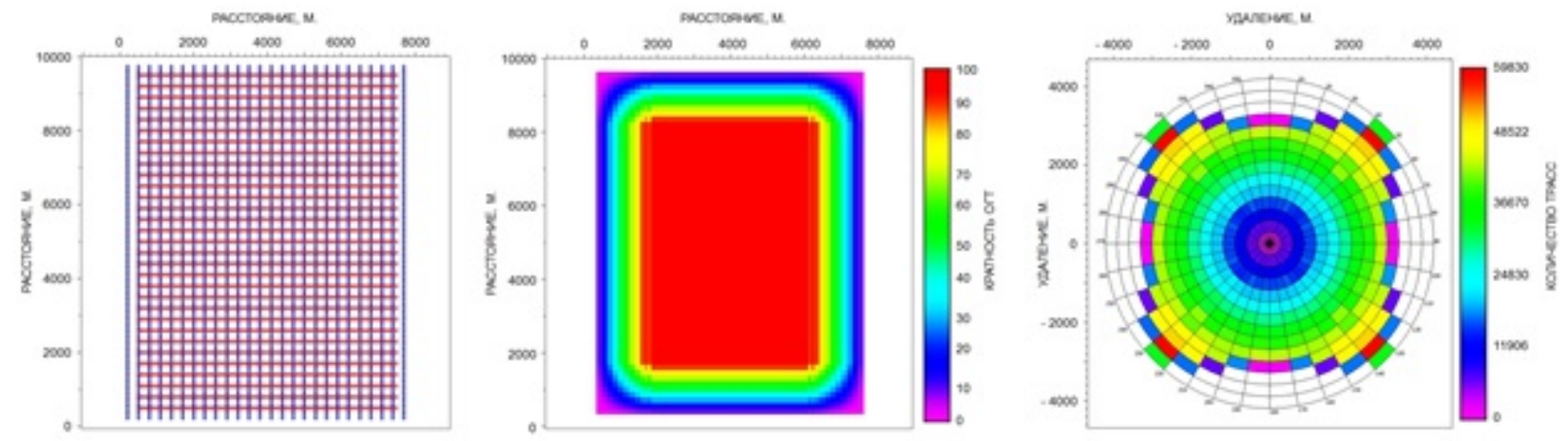


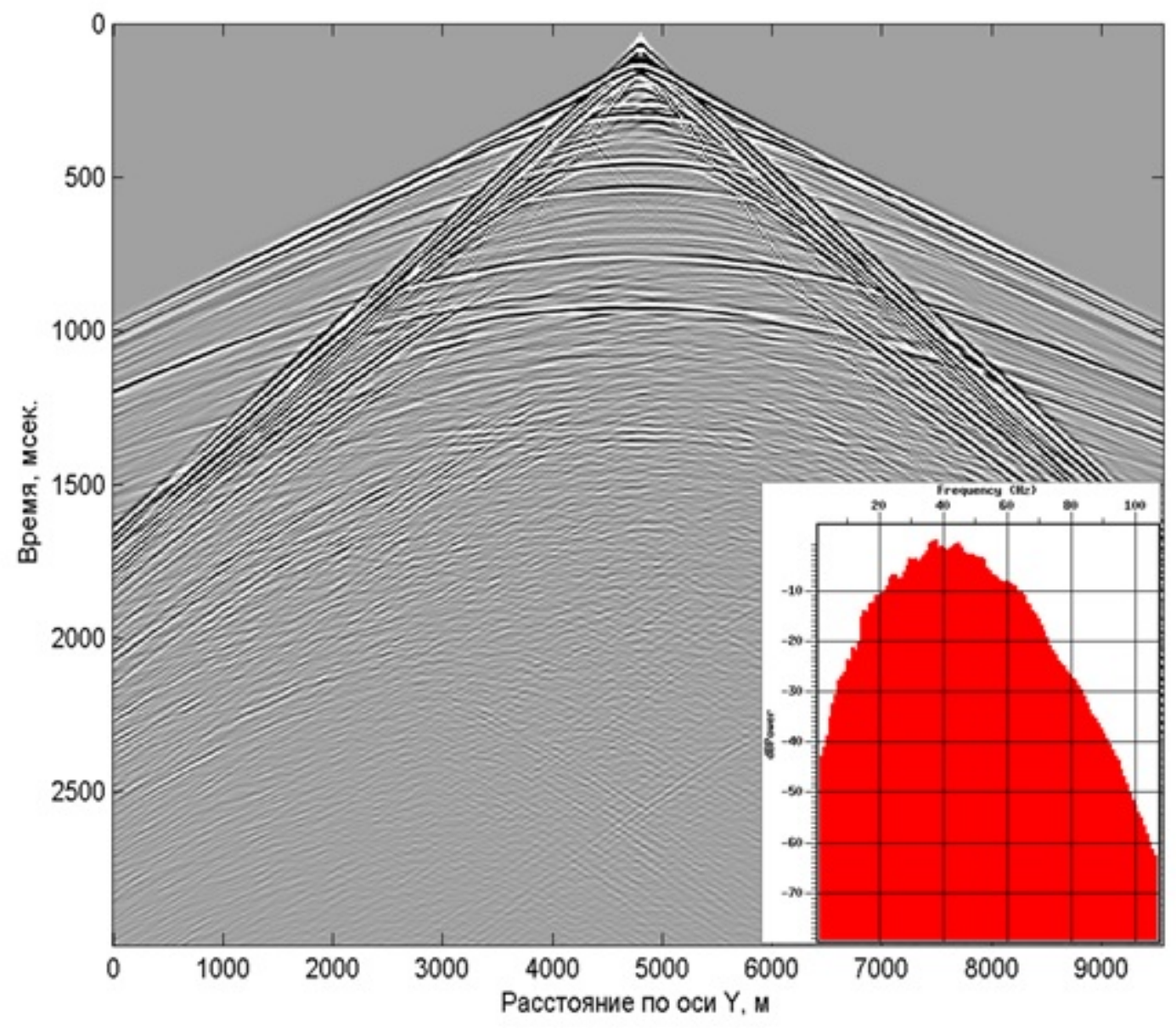




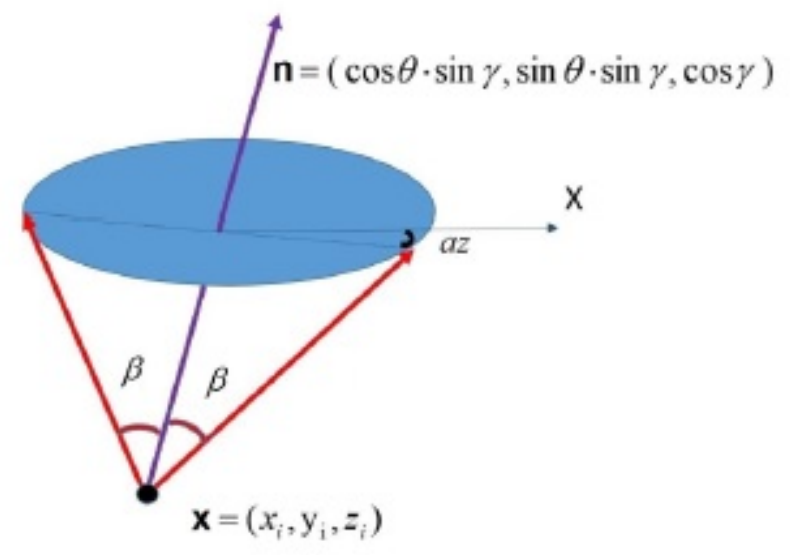




$$
\text { (4) }
$$



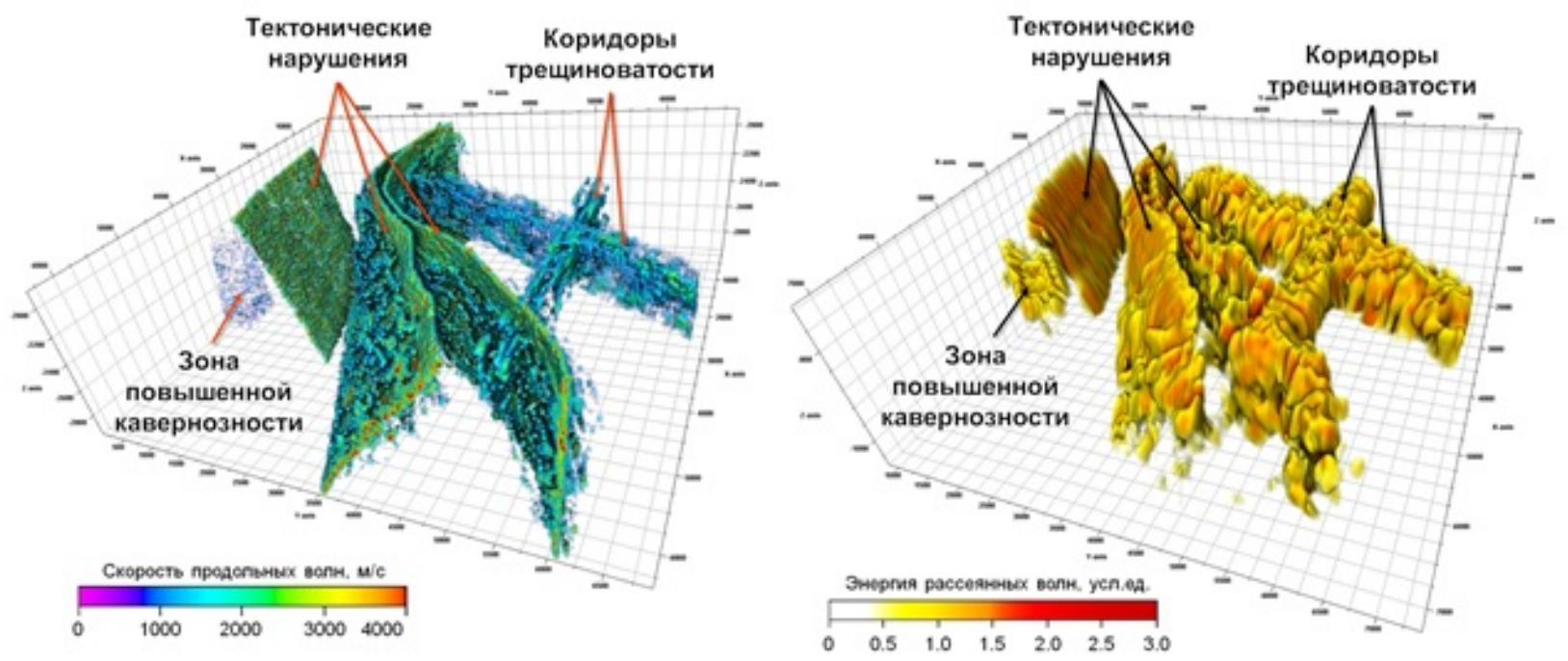

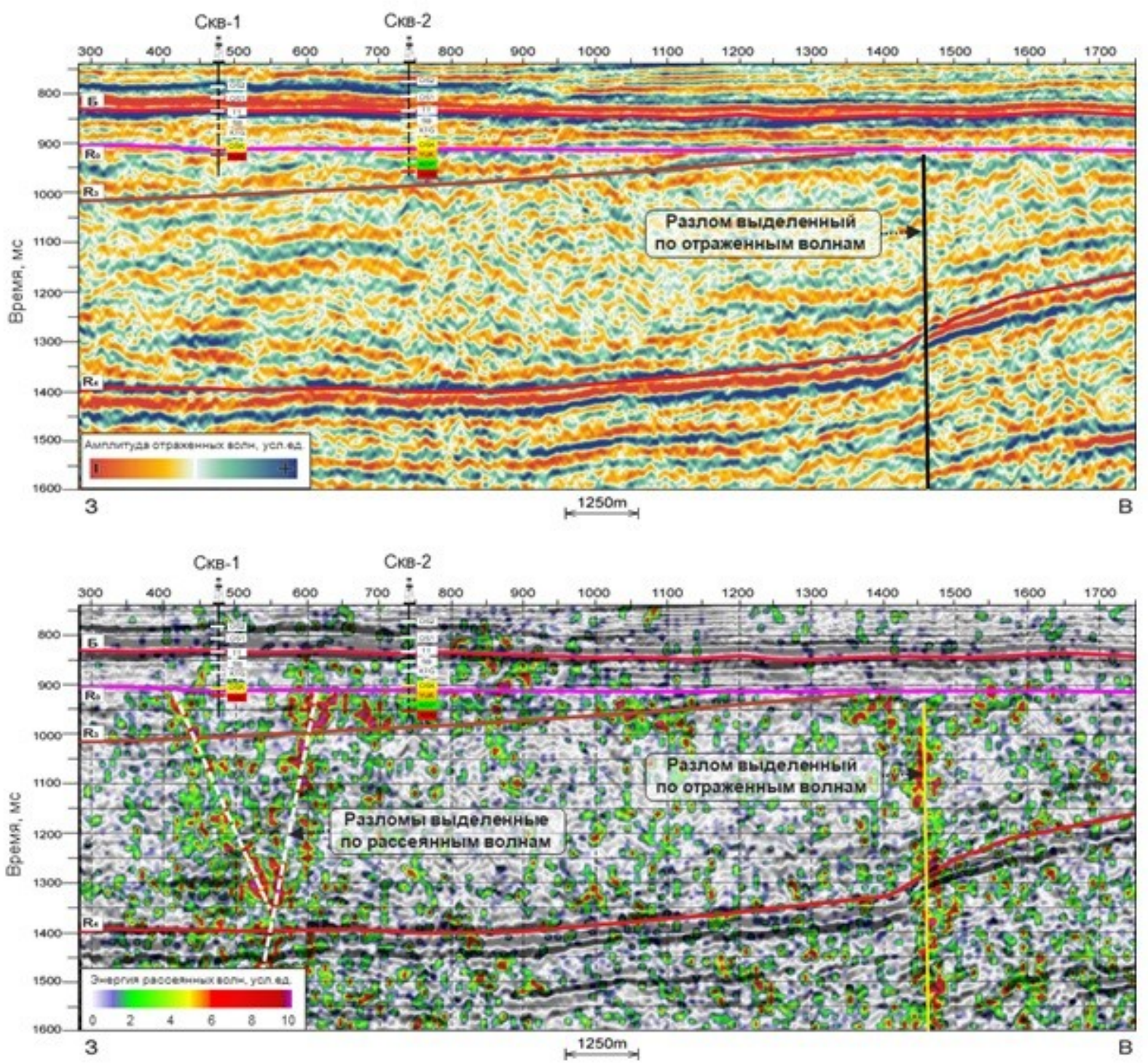

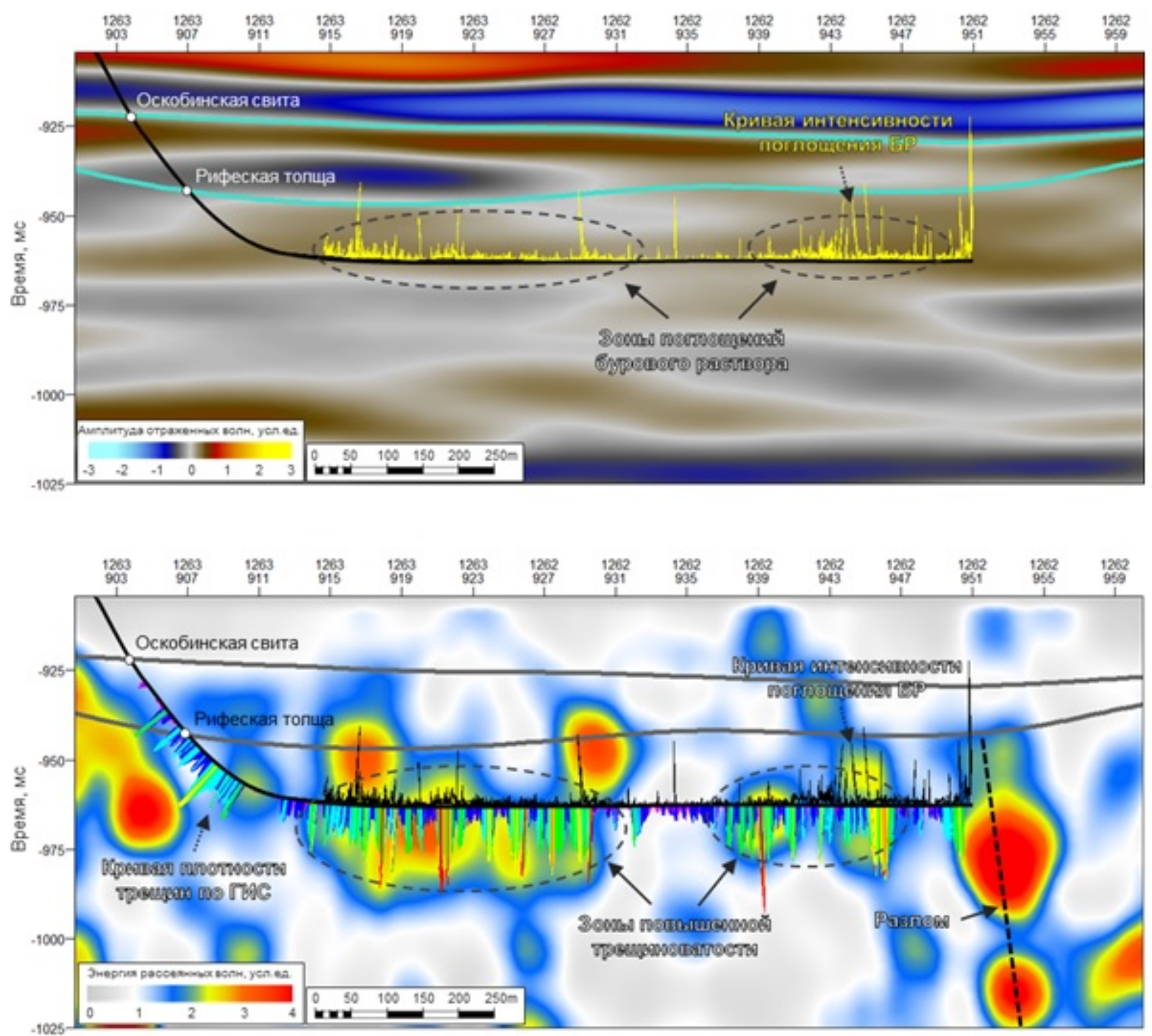